\title{
LA REUBICACIÓN DE SUBJETIVIDADES EN ESPACIOS MARGINALES \\ EN INSTRUCCIONES PARA SALVAR EL MUNDO
}

\section{THE RELOCATION OF SUBJECTIVITIES IN MARGINALIZED SPACES IN INSTRUCTIONS FOR SAVING THE WORLD}

\author{
JenNifer Brady \\ University of Minnesota-Duluth
}

\section{RESUMEN}

La novela de 2008 de Rosa Montero Instrucciones para salvar el mundo ofrece un mejor entendimiento de la relación compleja entre el espacio urbano y los seres humanos en el contexto de la España del siglo XXI. Después de que falleció su pareja, el protagonista de la novela Matías Balboa alterna entre espacios marginales en las afueras de Madrid en búsqueda de sí mismo. El ambiente liminal de esos espacios le ayuda a poder restablecer su subjetividad y, como consecuencia, abre la posibilidad de redefinir lo que es una comunidad colectiva. En este estudio se analiza la trayectoria de dos personajes según el marco teórico de los estudios urbanos, específicamente, de las ideas de Henri Lefebvre.

Palabras clave: espacio urbano, identidad, marginalización, Rosa Montero, subjetividad.

\begin{abstract}
The 2008 novel by Rosa Montero Instrucciones para salvar el mundo offers insight into the complicated relationship between urban space and human beings in the context of twenty-first-century Spain. After his wife passes away, the protagonist of the novel Matías Balboa alternates between marginal spaces in the outskirts of Madrid in search of himself. The transitory environment of such spaces helps him to be able to reestablish his subjectivity and, as a consequence, opens up the possibility of redefining the idea of a collective community. In this current study, the trajectory of two characters is analyzed according to urban studies theories, specifically those by Henri Lefebvre.
\end{abstract}

Keywords: urban space, identity, marginalization, Rosa Montero, subjectivity. 
La relación entre la experiencia de estar en el mundo y el ambiente que le rodea al ser humano es un tropo literario que se ha visto a lo largo de la historia de la producción cultural. Puede que haya varios tipos de espacios que afectan el desarrollo de la subjetividad, los cuales se puede agrupar según binarios como el espacio privado y el espacio público, el centro y la periferia, el espacio urbano y el espacio rural, el bullicio de la ciudad y la tranquilidad de la naturaleza, entre otros.

En la novela española contemporánea que se analizará en este estudio, Instrucciones para salvar el mundo (2008) de Rosa Montero, la relación entre el individuo y el espacio es complicada y da una vista profunda de la subjetividad de los dos personajes principales. Los espacios en la novela de Montero no ponen énfasis en el paso del tiempo ni se refiere a un pasado o glorificado o nostálgico; sin embargo, el momento del presente llega a ocupar gran importancia mientras los personajes interactúan con otros y examinan a sí mismos en varios espacios marginales en las afueras de la ciudad metrópoli de Madrid. Se ve no solo un presente estancado en la estasis del desarrollo subjetivo por la parte de los personajes, sino también un espacio urbano que los sitúa a la periferia de la capital española donde llegan a reflexionar sobre sus propias identidades. Estos sitios se construyen como espacios transitorios y les ofrecen la oportunidad a los personajes de la novela de resituar a quiénes son, o sea, de redefinir sus subjetividades.

El mundo del siglo XXI se forma por las presiones del capitalismo y de la globalización. Algunos estudios académicos recientes analizan la representación textual y fílmica de las consecuencias destructivas medioambientales por el ser humano en el contexto de España, las cuales se basan en cuestiones capitalistas y ecológicas (véase, por ejemplo, Prádanos). Se puede considerar también, como se hace en este estudio, las consecuencias del espacio liminal en el desarrollo y/o la destrucción del ser humano desde la perspectiva personal y subjetiva primero, y después, cómo la esfera individual llega a construir una consciencia nueva de la idea normativa de comunidad colectiva. Aunque treinta años han pasado desde el fin del franquismo el concepto de comunidad en España sigue basándose 
con frecuencia en las normas anticuadas de los efectos de la época de dictadura. Por ejemplo, suele continuar excluyendo a quienes vienen al país peninsular desde otros países, a las personas de orientación sexual queer y a ellos de creencias religiosas no cristianas. Lo que se ve en la novela de Montero, sin embargo, es un nuevo tratado con el espacio urbano de Madrid, uno que expande el concepto de comunidad para que las subjetividades muchas veces discriminadas quepan mejor dentro del escenario local madrileño y del mundo global en el cual todos vivimos. La intersección entre individuos con experiencias en el mundo distintas y el espacio urbano en el que habitan, por ejemplo, constituye una de las maneras de crear un nuevo tipo de comunidad contemporánea.

Para entender la posición del individuo en el ambiente urbano de Madrid Benjamin Fraser ofrece un análisis de las teorías de los estudios urbanos en su libro Henri Lefebvre and the Spanish Urban Experience: Reading the Mobile City. Fraser hace hincapié en las ideas globales de Lefebvre, quien se considera como uno de los fundadores de los estudios urbanos, cuando nos recuerda que "the city is better understood as a movement rather than a thing" (1). La crítica del espacio estático por la parte de Lefebvre abre la posibilidad de definir una ciudad como una entidad dinámica social, económica, política y cultural que está en constante transformación. Además, la idea de que el espacio urbano móvil funcione en relación con las personas que viven e interactúan dentro de ello (y no simplemente para el servicio de ellos) es un hilo conductor de toda la teoría lefebvriana. Según el análisis de Fraser, entonces, la ciudad es variable y está continuamente desarrollándose. Este carácter móvil depende de la reclamación de la vida cotidiana del individuo de los efectos del capitalismo. También los dos Fraser y Lefebvre reconocen las consecuencias del mundo contemporáneo según la necesidad de contemplar las dificultades de estar en el mundo y de poder reconciliar con ellas. Las tensiones del capitalismo contemporáneo han creado un sistema roto de la ciudad que favorece el intercambio de productos en vez del valor dinámico de los seres humanos. Algunas consecuencias incluyen la alienación del ser humano de su propia comunidad y de su propia consciencia y la forzada reexaminación de la subjetividad desde lo más interior del individuo después de experimentar una crisis personal.

Lefebvre ofrece una solución para la soledad de la vida diaria creada por los estreses capitalistas en su libro póstumo Rhythmanalysis que enfoca en la resituación del individuo como la prioridad dentro del sistema complejo de una ciudad. Lo que se denomina el ritmoanálisis rectifica el "death-dealing character" de los efectos del capitalismo en el espacio urbano al proponer un nuevo modelo de vivir en la ciudad, uno que se basa en lo 
humano, lo social y lo cívico y rechaza la fuerza impulsora económica del capitalismo (Lefebvre, Rhythmanalysis 53). Se debe notar que Fraser afirma que el concepto de Lefebvre del ritmoanálisis fue influido por Gaston Bachelard, quien aboga por la conexión íntima entre el espacio y la subjetividad, cuando escribe que "the idea of rhythmanalysis was borrowed from Gaston Bachelard (and before that from Portuguese writer Lucio Alberto Pinheiro . ..), and .. . Lefebvre had broached the subject earlier in both the second and third volumes of the Critique of Everyday Life" (29). El ritmoanálisis de Lefebvre (y la interpretación de él de Fraser) nos ayuda a conceptualizar la dinámica entre los espacios urbanos y la redefinición de subjetividades en la novela de Montero.

Enmarcada por los estragos de la globalización de vivir bien dentro de una ciudad que vacila entre un organismo vivo y dinámico y un espacio estancado y asfixiante, Instrucciones para salvar el mundo ofrece representaciones noveladas, pero verosímiles, del Madrid del siglo XXI. La demografía de la capital española ha cambiado en los últimos treinta años, pero debido al hecho de que es difícil descifrar el número exacto de personas de otros países en la capital por cuestiones burocráticas y políticas, no existe una cifra exacta. Lo que sí se puede estimar es que en 2015 alrededor de $10 \%$ de la población española era de otros países ("How Many"). El Instituto de Estadística informa que la población de personas empadronadas de otros países en la Comunidad de Madrid en 1986 fue 46.237. En 2014 esa cifra había aumentado a 879.953 personas, la cual representa un crecimiento promedio de alrededor de $11 \%$ cada año. Además, José Manuel Rodríguez Álvarez reporta que en la ciudad de Madrid en 2009 había alrededor de 575.000 personas de otros países, o un porcentaje de $17.5 \%$ de la población de la capital.

En la novela de Montero hay representaciones de personas de otros países y de españoles de varias clases socioeconómicas que viven e interactúan en la periferia de la ciudad. La comunidad multicultural y económicamente diversa que se presenta nos invita a meditar sobre la demografía cambiante de Madrid (y de la España en general). Nos hace preguntar: ¿̇cómo se ha cambiado la contextura de la conceptualización de "comunidad" desde la Transición democrática? Victoria L. Katz afirma que se puede describir una ciudad como una comunidad (o, en muchos casos, como varias comunidades) porque existen interacciones interpersonales cuando escribe, "Whether imagined or real, the city is much more than buildings and boundaries; it is a place where people congregate to form a community" (3). La composición del espacio urbano donde viven los personajes en la novela de Montero evoluciona en maneras distintas para los varios personajes. Lo que tienen en común es que los espacios liminales llegan 
a ser un refugio para ellos en varios sentidos: un refugio que les ofrece la oportunidad de situar las subjetividades y de crear una comunidad según pautas creadas por sí mismos.

A Rosa Montero (1951-), periodista y autora de quince novelas y muchos relatos y cuentos, se le han galardonado varios premios literarios en España y en Latinoamérica, incluyendo el Premio Primavera por su novela El hijo del caníbal (1997) y el Premio Mandarache por Historia del rey transparente (2007). Su obra trata una diversidad de temas, pero siempre desde una base feminista y desde el deseo de explorar diversas subjetividades. En Contemporary Feminist Fiction in Spain: The Works of Montserrat Roig and Rosa Montero, Catherine Davies nota que Montero expresa "a strong inside critique not only of the sexist practices of left-wing political parties but of other, more obvious Spanish patriarchal institutions (from the family and the Church, to the nightclub and the workplace)" (174). Analizar los pormenores del sistema institucional de España guía la crítica sutil de la esfera social que tiende llevar a cabo Montero en sus columnas periodísticas y en sus obras narrativas. El medio de este tipo de examinación en su obra de ficción es, con frecuencia, la examinación de la experiencia de ser humano en el mundo y en espacios distintos. Es decir, el análisis de subjetividades-cómo se forman y cómo se transforman según los espacios que ocupan-es uno de los temas centrales en su narrativa.

En Instrucciones para salvar el mundo Montero nos presenta a dos personajes que se encuentran en crises personales. Narrada desde la perspectiva de la tercera persona, la novela explora las vidas íntimas de Matías Balboa y Daniel Ortiz, hombres de edad media que sufren del desequilibrio de identidad por razones distintas, en maneras diferentes y con resultados distintos. La organización de la trama crea una vacilación entre ambas historias hasta que se entrelazan. Los capítulos de la primera mitad del libro suelen alterar entre la historia de Matías y de Daniel con algunas excepciones en las cuales hay dos capítulos contiguos que narran la historia de uno de los personajes. Después del clímax de la historia, cuando las líneas narrativas de los dos personajes se trenzan y los espacios marginales en las afueras de Madrid que ellos ocupan se cruzan con el secuestro de Daniel por la parte de Matías, la focalización de los capítulos abre a incluir más detalles de las historias de otros personajes narrados desde un narrador extradiegético con una perspectiva subjetiva.

La mayoría de Instrucciones para salvar el mundo toma lugar en espacios liminales en los alrededores de Madrid y en el espacio definido del Hospital San Felipe dentro de la capital donde trabaja Daniel. Muy acertadamente Luis I. Prádanos comenta sobre la representación de Madrid en la novela cuando escribe, "El contexto urbano que sirve de marco a la historia 
es un Madrid contemporáneo que incorpora elementos de la actualidad informativa más inmediata (el terrorismo global, el cambio climático, la soledad de la vida urbana, la inmigración masiva y un largo etcétera)" (47). Los efectos de globalización en el espacio en progreso de Madrid y en la demografía de la comunidad en evolución engendran las crises de subjetividades por las cuales pasan Matías y Daniel y les dan la oportunidad de resituar quiénes son dentro del paisaje cambiante.

Una de las consecuencias del capitalismo y de la globalización, como proponen Prádanos y Katz, es la soledad. Es efectivamente este sentido de alienación donde se encuentran Matías y Daniel. Los dos se vacilan entre espacios marginados mientras intentan reconciliar quiénes son. Matías, el protagonista de la novela y un hombre de cuarenta y cuatro años, intenta manejar la vida después de la muerte de su esposa Rita al cáncer. El luto llega a ocupar por completo la vida diaria de él y bloquea una y otra vez las pocas interacciones con otros personajes al principio de la novela. En el camino para poder reubicar quién es Matías se vacila entre varios espacios en las afueras de la capital española: la casa media hecha, el taxi, el centro de la ciudad (pero con frecuencia desde el refugio de su taxi), el hospital, los barrios castizos, el prostíbulo el Cachito y el bar el Oasis.

Como contraparte a Matías, Daniel forma parte de una clase social más alta. Funcionando como una construcción paralela en la novela, Daniel cumple cuarenta y cuatro años al principio de la novela tal como Matías. Es médico que trabaja en la sala de urgencias en el Hospital San Felipe, el mismo hospital donde trataban a la esposa de Matías antes de su muerte. Al principio de la novela Daniel ha entrado en una época de profunda depresión. Las acciones de él repetidamente muestran la apatía que se siente y ponen énfasis en la desconexión con el espacio que le rodea que él ha creado por sí mismo. Las primeras veces que los lectores conocen a Daniel él juega obsesivamente al videojuego Second Life con su avatar llamado Nilo y ahoga penas en otros vicios como tomar en exceso el alcohol y fumar los cigarrillos. Los vicios intentan ayudar a manejar la depresión y el juego intenta funcionar como sustitución de la vida verdadera: "Second Life, y ahí radicaba su atractivo, no era un juego: era una Segunda Vida, como indicaba su nombre. . . . Era como la vida real" (Montero, Loc. 349). En el juego su amante Lup, cuya personaje se transforma fluidamente de gata a mujer, le invita a participar en una sala de sadomasoquismo, pero Daniel no puede situarse dentro del mundo virtual aunque desea hacerlo. Como otras cosas en su vida-el trabajo en el hospital y su matrimonio con Marina (el narrador describe a ella como la "mutilación" de Daniel [Loc. 1337]), entre otras-Daniel llega a aburrirse del juego. Pronto sustituye el mundo fantástico del videojuego por la obsesión de una víctima del tráfico 
humano de Sierra Leona llamada Fatma que trabaja en El Cachito.

La vida cotidiana de Daniel no le ofrece ningún ritmo que alimente la subjetividad. Él no se integra en el movimiento orgánico de la ciudad; queda marginado, casi suspendido, de poder interactuar en el espacio urbano de Madrid. Lefebvre delinea los atributos de una persona que está alineada con la ciudad como alguien que

draws on his breathing, the circulation of his blood, the beatings of his heart and the delivery of his speech as landmarks. Without privileging any one of these sensations, raised by him in the perception of rhythms, to the detriment of any other. He thinks with his body, not in the abstract, but in lived temporality. (21)

Daniel no tiene éxito con vivir en el presente y su cuerpo físico nunca encarna los ritmos orgánicos de una ciudad. Siempre lucha en contra del ambiente a su alrededor, eligiendo quedarse separado del espacio urbano en espacios abstractos e hiperreales como le ofrece el videojuego. El narrador resume la relación apática de Daniel con la capital español en las siguientes líneas:

Estar haciendo cola para un cine y que se solara alguien. Estar haciendo cola con el coche para tomar una atestada salida de la M-30 y que se colaran un montón de caraduras. Llegar al aparcamiento del hospital y encontrarlo lleno. . . . A cada rato sucedía algo desconsolador, odioso, detestable, algo tal vez pequeño pero con suficiente capacidad para amargarte la vida. (Montero, Loc. 439)

La ciudad para él funciona en contra de él. La interacción difícil en el espacio urbano para Daniel no pinta una imagen de la ciudad orgánica como la describe Lefebvre y su cuerpo físico no le sirve como metrónomo que sincroniza la identidad con la ciudad (Lefebvre 19). Más bien, Daniel lucha contra el espacio urbano de la ciudad y, a la vez, no aboga por sí mismo al crear un nuevo espacio para meditar sobre su subjetividad.

Es evidente que el espacio personal que ocupa el médico es muy separado de la métrica de Madrid. En un momento el narrador relata que Daniel "[a]brió la ventana y aspiró la brisa de la madrugada; al fondo se oía el ruido del tráfico proveniente de las calles principales, un sordo rumor de aguas metálicas" (Montero, Loc. 463). La ciudad se describe como el Otro en estas contemplaciones de Daniel; es una ciudad mecánica según 
todos los sentidos. El nacimiento de un nuevo día en la cita de arriba no le ofrece una nueva oportunidad, sino que fortifica la relación separada que tiene el médico con la ciudad estática. El uso de sinestesia en la descripción del ruido del tránsito como "aguas metálicas" hace hincapié en la imposibilidad de Daniel de utilizar el cuerpo físico para conectarse con el espacio urbano. Otra vez escoge quedarse marginado. En otro momento, tomando la perspectiva de Daniel, el narrador comenta, "Qué extraño momento de la vida estaban viviendo: a lo peor hasta iba a ser verdad lo del calentamiento climático y lo de estar en las vísperas de un apocalipsis. A fin de cuentas, ¿̇no sentía Daniel que dentro de él naufragaba el mundo?" (Loc. 1360). La descripción del acercamiento del fin del mundo se identifica como un símbolo de la alienación de Daniel que él ha instalado para sí mismo. No hace nada para salvarse ni para cambiar la trayectoria de su observación apocalíptica de la capital española.

Una de las únicas maneras en la cual Daniel intenta conectarse con otros-pero continuamente fracasa-es a través de lo erótico subversivo en espacios marginados como el Second Life, el prostíbulo El Cachito y con Fatma, el objeto de su deseo erótico. Cuando Daniel trata a Fatma en Urgencias para curarle de una herida causada por su proxeneta Draco, las reacciones de él vacilan entre el placer erótico y la repugnancia física y psíquica (Loc. 823). Es un tema continúo a lo largo de la novela-en un momento el narrador declara que Daniel "quería experimentar la excitación del miedo" (Loc. 1734) - y los espacios marginados le ofrecen varias oportunidades aunque fracasa una y otra vez en cumplir con los objetivos, o sean eróticos o personales. No puede aceptar que él mismo es culpable para los fracasos.

Si los espacios de Second Life y de El Cachito le ofrecen a Daniel un escape irónico y inherentemente ineficaz de la realidad, Matías también reside en espacios de turbación fuera de las normas sociales tradicionales. Con esto dicho, Matías tampoco puede alinearse muy bien con el ritmo de la capital española al principio de la novela, pero a diferencia de su contraparte, él sí se siente la métrica del espacio urbano en su cuerpo físico. El narrador describe la experiencia física de Matías y el espacio urbano cuando declara, "La ciudad vibrara, se desdibujaba, palpitaba como una turbia masa viva al mismo compás del doloroso latido de sus sienes" (Montero; Loc 77). El ambiente del espacio urbano funciona como un espejo del estado anímico de Matías y viceversa. Lefebvre escribe que una persona que está afinada con el espacio de una ciudad encarna un cuerpo que "serves him as a metronome" (19). El instrumento para medir el tiempo de una composición musical como síntoma en el cuerpo físico hace hincapié en la crisis personal de Matías en la descripción de arriba del entretejimiento de las vibraciones urbanas y el dolor de cabeza que sufre el taxista. 
El ambiente despiadado de la capital les empuja a los dos personajes a ocupar espacios marginales de los alrededores de Madrid. Los espacios en las afueras de la capital española aíslan a Matías y le dan la oportunidad de reconciliar su identidad según pautas no tradicionales. Homi K. Bhabha describe un espacio comunal híbrido donde se expande la conceptualización de comunidad en su teoría del "third space" de su libro The Location of Culture como un espacio fluido que no forma parte del espacio normativo y donde se crea una nueva textura comunitaria a través de una posición no céntrica. Bhabha afirma que "there is a sense of disorientation, a disturbance of direction, in the 'beyond': an exploratory, restless movement caught so well in the French rendition of the words au-delà-here and there, on all sides, ... hither and thither, back and forth" (2). Aunque su teoría de "third space" refiere a un espacio colectivo se puede aplicarlo también a los efectos del espacio en la reexaminación de subjetividades individuales. El más allá (o el beyond) que describe Bhabha, por ejemplo, hace que Matías se encuentre con pocas oportunidades de involucrarse en interacciones con otros, creando un tipo de hibridez fracasada personal que él no puede manejar muy bien hasta el final de la novela. La situación transitoria creada por sí mismo al alternar entre varios espacios-la casa incompleta, el bar El Oasis, el taxi, las chabolas, entre otros-hace hincapié en su crisis de subjetividad. Sin embargo, al final el vaivén de su movimiento por esos espacios le guía a la oportunidad de reinventarse con éxito-de crear un espacio por sí mismo-mientras su contraparte Daniel continúa fracasando en el objetivo de autorreflexión.

Al principio de la novela Matías abandona su piso en el centro de Madrid y se muda a la casita media hecha que construía con su esposa en un vecindario nuevo lejos del centro de Madrid. La casa incompleta se localiza en un espacio ambiguo, uno que no forma parte del núcleo de la ciudad, sino de los límites. Atando el espacio íntimo del hogar con la geografía de la subjetividad, en The Poetics of Space Bachelard escribe que la casa debe ser "the topography of our intimate being" (xxxvi). El ambiente del espacio marginado de la casa incompleta de Matías funciona como un espejo de los sentimientos de él y de su posición marginada sin conexiones familiares y amistosas en la comunidad normativa de Madrid. El narrador describe la ubicación de la casa incompleta en las siguientes líneas: "La casa de Matías se encontraba al final de una modesta urbanización. Se trataba de un enclave aislado. . . . [L] a calle no era más que un desmonte sin asfalto ni aceras, con un muro mugriento que separaba la colonia de las tierras pertenecientes al municipio vecino" (Montero, Loc. 278). En esta descripción se hace hincapié en el espacio marginalizado del barrio ya periférico, lo cual abre la posibilidad a un tipo de una doble marginalización. 
El estado incompleto de la casa se repite en detalle por lo largo de la novela, como en la siguiente descripción:

La casita estaba ya techada, las ventanas y la puerta exterior estaban colocadas, los radiadores instalados, el baño de abajo terminado. Pero faltaban las puertas interiores, y la cocina, y pintar, y el suelo era sólo puro cemento. Disponía de electricidad, pero su única fuente de iluminación consistía en una bombilla en el extremo de un cable muy largo, y el agua venía de la toma del jardín por medio de una manguera verde. . . [ [L]a casa, pequeña y maciza, parecía una muela solitaria en la mandíbula de un viejo. (Loc. 109-110)

La condición incompleta de la casa refleja el estado de estancamiento de Matías en un espacio personal de crisis del cual no puede remediar. Bachelard sostiene que la casa ofrece el ambiente ideal para poder analizar la subjetividad, notando que la casa está compuesta de más de solo las partes mensurables y descriptibles:

It is not a question of describing houses, or enumerating their picturesque features and analyzing for which reasons they are comfortable. On the contrary, we must go beyond the problems of description-whether this description be objective or subjective, that is whether it gives facts or impressions - in order to attain the primary virtues, those that reveal an attachment that is native in some way to the primary function of inhabiting. (4)

La experiencia de Matías de residir en una casa incompleta que construía con su pareja ahora fallecida crea un espacio que carece del cariño y de la intimidad a los que alude Bachelard, pero sí, donde sobran las descripciones negativas del ambiente desfavorable como pruebas del estancamiento del taxista.

Las repetidas menciones del frío del espacio de la casa media hechapor ejemplo, "un frío atroz" y "[u]n frío sepulcral" (Loc. 110)-ponen en tela de juicio el estado anímico de Matías también. El frío de la casa y la depresión del protagonista se acoplan para alegar el estancamiento personal de él. Como otro ejemplo de la inmovilización de Matías a través de la voz narrativa él mismo afirma, "No pienso terminar jamás esta casa", y interviene el narrador para confirmar la declaración al notar, "Y tenía razón, nunca la acabaría" (Loc. 118). Esta aseveración pone énfasis en el 
fracaso forzado de su matrimonio por la consecuencia de la enfermedad mortal de Rita. Los dos, su matrimonio y la casa, siempre estarán en un estado estancado sin posibilidad de un futuro.

La imposible final feliz se complica aún más al describir la casa como una cárcel. El espacio enclaustrado profundiza el estado aislado de Matías. La casa se pinta como una jaula simbólica que representa la estasis de Matías en su nueva posición de viudo y como una cárcel presagiada del secuestro de Daniel por la parte de Matías. El narrador describe el ambiente penitenciario al afirmar que "[l]a ventana tenía rejas y se arrepintió de haberlas instalado, porque ahora potenciaban su sensación de asfixia y de opresión. Todo estaba mal. Todo estaba muy mal" (Loc. 270-78). La sensación de cárcel se repetirá más tarde cuando a través de la voz del narrador el secuestrado Daniel contempla la mala condición de la casa: "en efecto, Daniel se sintió gorila, se sintió simio, encerrado tras las rejas de la ventana e incapaz de llamar la atención de los humanos" (Loc. 2674). Encerrado dentro del espacio adverso, Daniel mira al barrio por la ventana de la casa de Matías y, desde la voz narrativa, medita, "Era un lugar desolador, el fin del mundo" (Loc. 2626). La metáfora aquí es llamativa: la casa como una cárcel representa el estado psíquico estancado de los dos personajes. Sin embargo, en un sentido irónico la casa incompleta en un lugar marginal de las afueras de Madrid saca a Matías y a Daniel del espacio urbano del centro de la ciudad, situándolos con la posibilidad de empezar a examinar a sí mismos según normas no tradicionales. Como un espejo del momento de sus vidas la casa es un lugar transitorio en un espacio apartado del centro de la ciudad que encarcela-e intenta liberar-a los dos personajes.

Una lectura simbólica de la ubicación de la casa incompleta se vincula con la profesión de taxista de Matías. La vida privada de él se hospeda mayormente en estos dos espacios transitorios, el de la casa y el del taxi. Los dos espacios liminales se describen repetidamente como refugios, pero no son refugios típicos. A todo lo contrario, son lugares que carecen de cariño y de paz. El narrador describe la reclusión de Matías en los espacios herméticos de la casa y del taxi cuando cuenta que él "se había metido dentro de una cáscara de soledad suprema que le rodeaba como una armadura: el vacío de su chalé a medio hacer, la burbuja de ensimismamiento en la que vivía, el aislamiento de su taxi, esa caja rodante dentro de la cual él iba encerrado" (Loc. 573-81). La casa incompleta y el taxi amparan irónicamente su crisis personal. Influenciado por las teorías del espacio de la casa como refugio de Bachelard en su artículo "A Developed Nature: A Phenomenological Account of the Experience of Home," Kirsten Jacobson escribe que el hogar "protects us temporarily from the interests and demands of others. In this way, home is a place of self-nourishment and 
self-development" (359; énfasis en el original). En el caso de Matías los espacios de la casa y del taxi, que deben ser refugios para poder llevar a cabo sus objetivos de autorreflexión, primero funcionan como espacios que lo aíslan aún más del mundo. Matías pasa por momentos muy bajos, pero, en una manera irónica por el mal estado de la casa y por el carácter transitorio del taxi, son ellos los primeros espacios marginales que le ofrecen la oportunidad de explorar los detalles de su crisis personal. Efectivamente, pasar por el ambiente desunido de la casa y del taxi le ayuda a poder examinar quién es más tarde en la novela.

Dos otros espacios marginados, el bar El Oasis y el prostíbulo El Cachito, ubicados en la carretera de Madrid a La Coruña, también funcionan como espacios alejados de la esfera urbana en los cuales Matías empieza el camino a la restauración de su identidad. El Oasis se describe como "un bar de ambiente familiar, aunque se tratara de una familia un poco triste" (Loc. 549). Trabajan allí Luzbella, la mujer que será la futura pareja de Matías, y Cerebro, una mujer mayor y alcohólica que antes era científica famosa. Además, Fatma, la prostituta forzada que trabaja en El Cachito, llegará a confiar en Matías cuando él le ayuda a liberarse de la esclavitud sexual de Draco.

En el espacio marginado del bar El Oasis Cerebro le cuenta a Matías varias teorías científicas basadas en la entropía del orden del mundo. Estas teorías sirven para conectar a Matías con el espacio que le rodea, lo cual le posibilita la reexaminación de su subjetividad. Cerebro le explica en detalle profundo la ley de Kammerer: "una ley física general que hace que el universo tienda hacia la unidad" (Montero, Loc. 683). Le dice que Kammerer fue influenciado por las teorías de Lamark, quien formalizó que "los seres vivos podían adquirir caracteres físicos a lo largo de su vida para adaptarse al medio y que luego eran capaces de transmitir esos cambios a sus hijos" (Loc. 650). Cerebro también le menciona la teoría de Lovelock a Matías una noche en el bar: "el universo tiene a la entropía, hasta alcanzar un punto de equilibrio en el desorden. ... [D] alguna manera, la vida introduce el orden en el mundo" (Loc. 1 142). Estas explicaciones científicas de las interacciones entre seres humanos dentro del espacio vivo de una comunidad le llaman mucha la atención a Matías. ¿Empieza a entender al escucharlos que el mundo es mucho más amplio que los microespacios enfermos donde reside él? La acumulación de coincidencias de crear un tipo de orden puede ser una de las cosas que influencia a Matías a secuestrar a David en la casa incompleta, la persona que él piensa es responsable por la muerte de Rita.

Los discursos de Cerebro en el bar también puede ser una de las razones por las cuales Matías tiene éxito en restablecer la subjetividad. Con el caos viene la armonía como declara Cerebro al delinear la teoría del efecto Lot del científico Fieldman: 
los seres vivos conformaban una unidad energética; que, de algún modo, todas las criaturas estábamos intercomunicadas, desde la mosca del vinagre al Papa de Roma, y que, dependiendo de lo que hiciéramos, contribuíamos a ordenar la matera y crear armonía, o bien a desordenarla y a desatar atronadores procesos de inestabilidad y furias caóticas. (Montero, Loc. 2526)

Yi-fu Tuan escribe en Space and Place: The Perspective of Experience que "[s]olitude is a condition for acquiring a sense of immensity" (59). Esta idea complementa las teorías científicas que presenta Cerebro a Matías. Al entender que el mundo que le rodea es armónico por su caos-que es dinámico por su inestabilidad-Matías se da cuenta de que él forma una parte integral de ese sistema y este entendimiento le empuja a reconciliar la tristeza y la soledad de perder a Rita. En este sentido encuentra de nuevo su ritmo en el espacio solitario en los lugares liminales de las afueras de la capital española.

Meditando sobre la variedad de la experiencia humana en un marco espacial Lefebvre proporciona lo siguiente:

Pleasure and joy demand a re-commencement. They await it; yet it escapes. Pain returns. It repeats itself, since the repetition of pleasure gives rise to pain(s). However, joy and pleasure have a presence, whereas pain results from absence (that of a function, an organ, a person, an object, a being). Joy and pleasure are, they are being; not so suffering. Pessimists used to affirm the opposite: only suffering is, or exists. (12; énfasis en el original)

Los varios espacios marginados por los cuales pasa Matías le hacen vacilar entre emociones binarias y entre experiencias de ausencia y de presencia. Al examinar los espacios liminales de su propio ser y de su propia experiencia en sitios geográficamente marginados en las afueras de $\mathrm{Ma}$ drid, Matías contempla el mensaje de las teorías científicas que le describe Cerebro. Parece que Matías empieza a estar en el mundo en una manera dinámica en vez de solo existir pasivamente dentro de un espacio estático porque entiende que el mundo-o sea, la comunidad-es un espacio híbrido donde todas las personas tienen valor y no importan ni sus experiencias pasadas ni si son el Papa de Roma o "la mosca de vinagre" como explica la ex-científica en El Oasis (Montero, Loc. 2526).

Otro momento en el cual Matías llega a ser consciente de su posición dinámica en el espacio es cuando las gorilas de Draco le hace conducir a las 
afueras de la ciudad y le dan un golpazo. Llegan "hasta las proximidades de la carretera de Andalucía" (Loc. 2877), o sea, hasta otro polo marginado y alejado, esta vez al sur de la capital. La violencia hacia su cuerpo le hace reflexionar sobre la muerte de Rita y está allí donde continúa la reconciliación de su vida, en ese espacio liminal. En el más allá y con su cuerpo físico herido Matías se siente

una especie de alivio. Una sensación de agotado descanso, como si llevara meses corriendo sin parar y por fin se hubiera detenido. . . . El ojo izquierdo del taxista empezó a manar lágrimas, un agua tranquila que le resbalaba por el puente de la nariz y caía sobre el polvo. Una lluvia fértil capaz de hacer crecer la puente de la hierba en el desierto de hormigas. (Loc. 2934-42)

En el espacio liminal de la carretera a Andalucía Matías experimenta un momento de estar con sí mismo y de meditar sobre quién es. Allí al lado de la carretera que sale de Madrid se podría interpretar las lagrimas de él como un bautizo simbólico, o sea, un tipo de renacimiento personal. La esperanza del futuro sube a la superficie de la descripción de entendimiento personal al darse cuenta de que él mismo-simbolizado por las lagrimas de su cuerpo físico-es capaz de construir una puente metafórica hacia el futuro y a un espacio más fecundo. Ese nuevo espacio será uno que alimente los rincones más profundos de su identidad.

En la próxima escena, Matías se sube al taxi y regresa a la casa incompleta para liberar a Daniel. El camino desde el sur de Madrid donde experimentó Matías una comprensión profunda de su subjetividad hacia las afveras al norte de la capital le da tiempo de reflexionar sobre el ambiente que le rodea y consecuentemente sobre su subjetividad. El narrador describe el paisaje a su alrededor y la salida del sol que envuelve al nuevo Matías durante la trayectoria hacia su casa en las siguientes líneas:

Una vaga sensación de náusea y de mareo impregnaba la escena de irrealidad. Frente a él, los últimos rayos de sol iluminaban el vertedero, arrancado destellos de las chatarras y los cristales rotos y convirtiendo el torrente de detritus, por unos segundos, en una hermosa alfombra. fulgurante. (Montero, Loc. 2967).

La luz en esta descripción representa la oportunidad para Matías de conocer de nuevo a sí mismo. Las instrucciones para salvar el mundo a las cuales se refiere el título de la novela llegan a ser más claras en esta escena de autorreflexión y después de las charlas científicas de Cerebro sobre la dinámica escondida en el espacio: la salvación mundial solo viene con el 
entendimiento personal. Con restablecer la subjetividad se puede empezar a reconstituir que es una comunidad según pautas nuevas, como hace Matías al final de la novela.

Se ven las chabolas de las afueras de Madrid varias veces pero solo entran una vez Matías y Daniel en ellas. La primera vez que se acercan esos espacios marginales Matías lleva a un hombre en el taxi al barrio. El barrio, que se conocerá más tarde en la novela como El Poblado, se describe en esa primera instancia como "la barriada más peligrosa de Madrid" (Montero, Loc. 508) por su ubicación periférica y por no cumplir con las reglas hegemónicas del urbe (por ejemplo, no hay regulación de la policía y no hay infraestructura como las luces y el agua en esos barrios marginados). Pilar Valero-Costa escribe que estos barrios castizos que se ven en la novela "se han convertido en el asiento de inmigrantes y representan la fluidez cultural acentuada por la inminente permanencia de 'los nuevos' que ha cambiado la faz de los barrios" (31). Como sus contrapartes humanas, el espacio de las chabolas en Instrucciones para salvar el mundo se define también como el Otro aunque suele notar que los lectores no conocen ningún inmigrante que viva en las chabolas. Sin embargo, se da cuenta más tarde de que Draco, el proxeneta de Fatma, nació y vive allí. Draco es español de nacimiento y nunca se conoce su etnicidad. Él ocupa una posición marginada y violenta en la sociedad debido a su profesión en un espacio geográfico marginado fuera del centro de Madrid.

En la primera escena en la cual Matías se acerca El Poblado él "circulaba por los desolados desmontes del noroeste de la $\mathrm{M}-40$ con un pasajero de catadura siniestra a sus espaldas" (Montero, Loc. 492). El pasajero refleja los estereotipos de ese lugar marginalizado mientras que las luces del centro de la ciudad empiezan a disminuir: "Al fondo se veía la línea de la ciudad, los novísimos rascacielos a medio encender y el resplandor anaranjado de las luces urbanas, que, pegado al perfil del horizonte, parecía el vaho de la respiración de los edificios" (Loc. 500). Al llegar más cerca de El Poblado la oscuridad envuelve todo el espacio y la pared que separa el espacio marginado del espacio céntrico de Madrid forma una frontera explícita entre los dos espacios. El narrador describe que "entre las sombras [aparecían] un mar ondulado de chabolas" (Loc. 508) y "una muralla defensiva que nadie se atrevía a cruzar" (Loc. 516). Como el espacio liminal le empuje a hacer con frecuencia, durante este viaje a las chabolas Matías medita sobre la muerte de Rita y empieza a obsesionarse con "encontrar una explicación para lo inexplicable, una justificación" de la pérdida de su pareja (Loc. 516). El movimiento del vaivén a varios espacios marginales por la parte de Matías -y además, a espacios incrementalmente más marginados-le da la posibilidad de empezar a autorreflexionarse. 
Matías, con su compañero Daniel, entra otra vez en El Poblado para llevar a cabo un acto definitivo de benevolencia: van a la casa de Draco para comprarle la libertad de Fatma porque ella está embarazada y quiere dar luz al bebe. El narrador describe el camino periférico a la casa de Draco en El Poblado en las siguientes líneas:

en vez de ir hacia la autopista dieron la vuelta por un camino de grava y desembocaron en la pequeña carretera que atravesaba los sucios desmontes y que, carios kilómetros más adelante, pasaba por la zona salvaje suburbial, por los feroces asentamientos de chabolas y hogueras. (Montero, Loc. 3222).

La descripción del más allá dibuja una imagen del espacio marginado disparejo, contaminado y salvaje. Además, el espacio se conecta con la sensación de peligro del acto-"el aire de la noche estaba saturado de malignidad y de peligro" (Loc. 3239)-y se describe como un espacio infernal cuando el narrador observa que Fatma, quien "conocía bien el infierno, comprendió enseguida que estaba nuevamente dentro de él" (Loc. 3246). En el espacio marginado Matías tiene éxito en comprarle la libertad a Fatma. Tan pronto como cumplir con el objetivo, es obvio que ella tiene que salir de Madrid. Se sube a un tren para Zaragoza; es necesario que ella abandone el espacio violento de El Cachito y del barrio castizo y que encuentre otro espacio para poder empezar la vida de nuevo con el bebe que nacerá pronto.

El vaivén entre espacios marginados le concretiza para Matías el conocimiento que tiene que cambiar su vida, o sea, redefinir la subjetividad. Hacia el final de la novela al pasar por su casa incompleta en camino a la estación de trenes, Matías medita sobre el estado de la casa y, a la vez, contempla el estancamiento de su subjetividad:

la ausencia de muebles y de cama, el arrugado revoltijo de mantas tirado en un rincón, el suelo de cemento sin embaldosar, las paredes sin pintar, la sórdida bombilla polvorienta colgando del cable como un ahorcado. Un lugar miserable, no demasiado distinto de la turbia miseria del Poblado. (Montero, Loc. 3372-35)

Otra vez la casa incompleta de Matías simboliza la depresión profunda en la que había entrado Matías después de la muerte de Rita. Meditar sobre ese espacio liminal después de haber entendido que existe un futuro en 
la escena violenta en la carretera al sur libera a Matías. According to Tuan, "Spaciousness is closely associated with the sense of being free. Freedom implies space; it means having the power and enough room in which to act. Being free has several levels of meaning. Fundamental is the ability to transcend the present condition" (52). El ambiente sofocante que le había enclaustrado antes sirve para liberarle de la cárcel proverbial donde había residido entre la pérdida de Rita y el momento actual.

Con este sentido de tranquilidad Matías va a El Oasis para comer y ostensiblemente para despedirse de ese espacio liminal. Durante esta última visita, desde su perspectiva nueva Matías nota que el bar era entonces "un lugar más alegre, más acogedor, incluso más nuevo" (Loc. 3515). Allí hace una conexión amorosa con Luzbella que lo libera definitivamente de la tristeza y del aislamiento que había ocupado su cuerpo: "Matías se sintió un apretón por dentro, un repentino calor en el estómago. . . . Era alegría. Le pareció que Rita salía de dentro de él, que dejaba de pesarle en el pecho" (Loc. 3556). El alivio que se siente el taxista es físico; la presión de tanta soledad y del auto-aislamiento que había establecido para sí mismo desaparece, liberando a Matías a poder continuar viviendo la vida.

Matías tiene éxito en restablecer quién es porque pasó por varios espacios marginados. Al final de la novela su subjetividad no se ancla en una comunidad normativa, sino en un nuevo concepto de comunidad que él crea con la relación íntima con Luzbella. Su relación amorosa no sigue las normas sociales antiguas porque ella es inmigrante de Colombia y madre soltera. En este sentido Matías ofrece una definición nueva de qué significa ser español y qué puede ser la familia española.

Al contrario de Matías, Daniel no toma ventaja del movimiento entre espacios para reconsiderar quién es. Sin embargo, las sensaciones corporales de él son semejantes a las de Matías al final de la novela, como por ejemplo cuando el narrador describe la libertad de él en términos corporales: "Daniel sintió un enorme vacío en su interior. . . . Era una sensación vertiginosa y atractiva, como el deseo de arrojarse al aire que a veces se experimenta al borde de un abismo" (Loc. 3392). El médico promete cambiar la vida-de divorciarse de Marina y de dejar de hacer los vicios-pero los lectores se enterarán para el final de la novela que fracasa. A diferencia de su contraparte Daniel no puede restablecer su identidad y sigue viviendo con una subjetividad fragmentada y en crisis, escapando del espacio urbano otra vez en otros espacios como el videojuego Second Life. El espacio hiperreal le ofrece un escape falso de poder vivir una vida auténtica.

La novela termina atando el hilo de como empezó: con una generalización sobre el estado de la Humanidad. Si al principio el narrador nos 
afirma que la "Humanidad se divide entre aquellos que disfrutan metiéndose en la cama por las noches y aquellos a quienes les desasosiega irse a dormir" (Montero, Loc. 22) al final de la novela el mensaje se vincula con las contemplaciones de Cerebro del universo como un espacio donde la entropía hace que se forme orden dentro de la caos. Al final de la novela el narrador declara que "la Humanidad se divide entre aquellos que saben amar y aquellos que no saber" (Loc. 3573). Después de pasar por varios espacios marginados en las afueras de Madrid Matías se da cuenta de que se encuentran las instrucciones para salvar el mundo dentro de él mismo. Libera a Fatma, cuyo hijo llegará a ser científico que diseña un sistema para absorber dióxido de carbono del mar, una invención que contribuirá a "la lucha contra el calentamiento global" (Loc. 3384), y cuidará de Cerebro hasta su muerte varios años después. Además, llegará a saber amar otra vez al dejar de luchar contra las presiones urbanas y personales que le habían rodeado antes.

En Instrucciones para salvar el mundo los espacios marginados como la casa incompleta de Matías, el taxi de él, las carreteras que salen de Madrid, el bar El Oasis, el prostíbulo El Cachito y los barrios castizos como El Poblado no solo representan la demografía cambiante de Madrid en los años recientes, sino también ofrecen la oportunidad de establecer de nuevo la subjetividad y consecuentemente un nuevo concepto de comunidad. Pilar Valero-Costa concluye su estudio al escribir que en la novela de Montero "[l]os personajes, en lugar de reaccionar negativamente ante la otredad dejándose llevar por un proceso de racismo y xenofobia, toman una nueva postura: extienden la mano para ayudar y proporcionar encuentros interpersonales caracterizados por solidaridad y camaradería" (47). Matías tiene éxito al final porque empieza a entender el mundo como una serie de consecuencias que le llevan a conceptualizar en una manera nueva quién es y cómo cabe dentro del mundo, o de la comunidad. Ellen Mayock comenta sobre el éxito de este mensaje al final de la novela cuando escribe que

Montero successfully puts forth the idea of a world prostituted by individualism and corporate greed, a world that at times seems irrevocably and apocalyptically negative and demoralizing, but then characteristically lights the narration with the Lot effect, with occasional acts of kindness that make a difference ... and asks [readers] to consider complex questions of human existence. (170)

Los espacios herméticos le llevan a Matías a experimentar una apertura personal y, como resultado, colectiva. Las consecuencias de su auto-explo- 
ración se ven en el establecimiento de una comunidad nueva: el taxista español le ayuda a mejorar la vida a una prostituta forzada; se enamora de una madre soltera colombiana y llega a ocupar la posición paternal que tanto había querido antes pero que no podía obtener con Rita; y cuida de la vieja Cerebro hasta su muerte, lo cual se puede interpretar como el fin de la vida que él había deseado para su madre biológica con quien perdió contacto. En Instrucciones para salvar el mundo solo es posible llevar a cabo la construcción de esta comunidad multicultural y de clases económicas y edades distintas en los espacios marginales de las afueras de Madrid. El resultado es algo muy positivo para Matías y fortalece uno de los mensajes principales de la novela: para salvar el mundo, aun los microespacios dentro del mundo, hay que forjarse un espacio alejado de las normas sociales anticuadas para poder restablecer la agencia de la subjetividad y construir un nuevo concepto de comunidad.

En este sentido la autoexaminación que Matías lleva a cabo en los espacios marginados lo ancla en un momento de presencia, reubicando a sí mismo en una topografía íntima y colectiva. Al meditar sobre las consecuencias del espacio en la reclamación de subjetividad, él explora los binarios de los espacios y la relación del ser humano con el ambiente que le rodea en una manera personal y según el contexto específico de la capital española contemporánea.

\section{Bibliografía}

DAVIES, Catherine. Contemporary Feminist Fiction in Spain: The Works of Montserrat Roig and Rosa Montero. Oxford: Berg, 1994.

Estudio longitudinal de extranjeros (ELE) 2001-14. Instituto de Estadística. PDF. 11 feb. 2016.

FRASER, Benjamin. Henri Lefebvre and the Spanish Urban Experience: Reading the Mobile City. Lewisburg: Bucknell UP, 2011.

"How Many Foreigners Live in Spain and What are Their Nationalities?" Spanish News Today. 07 jul. 2015. Web. 11 mar. 2016.

JACOBSON, Kirsten. "A Developed Nature: A Phenomenological Account of the Experience of Home." Continental Philosophy Review 42.3 (2009): 355-73.

KATZ, Victoria L. "Urban Peripheries: Toward a New Vision of a Multicultural Community in Rosa Montero's Instrucciones para salvar el mundo". Toward a Multicultural Configuration of Spain: Local Cities, Global Spaces. Ed. Ana Corbalán and Ellen Mayock. Lanham: Fairleigh Dickinson UP, 2015. 3-13. 
LEFEBVRE, Henri. Rhythmanalyisis. Trans. Stuart Elden and Gerald Moore. London: Continuum: 2004.

MAYOCK, Ellen. "West Meets East in Rosa Montero's Instrucciones para salar el mundo." Cuaderno internacional de estudios humanísticos y literatura 16 (2011): 162-71.

MONTERO, Rosa. Instrucciones para salvar el mundo. Barcelona: Penguin. 2015. Kindle.

PRÁDANOS, Luis I. "La degradación ecológica y social del espacio urbano en Instrucciones para salvar el mundo de Rosa Montero". Letras femeninas 39.2 (2013): 45-61.

RODRÍGUEZ ÁLVAREZ, José Manuel. "Local Strategies for Immigrants' Integration in Spain: Case Studies of the Cities of Madrid, Barcelona and Bilbao." n.d. PDF. 11 mar. 2016.

TUAN, Yi-Fu. Space and Place: The Perspective of Experience. 1977. Minneapolis: $U$ of Minnesota P, 2003.

VALERO-COSTA, Pilar. "Cosmofobia, de Lucía Etxebarria e Instrucciones para salvar el mundo, de Rosa Montero: Complejidad cultural en la España global". La mujer en la literatura del mundo hispánico. Ed. Juana Alcira ARANCIBIA y Rosa TEZANOS-PINTO. Westminster: Instituto literario y cultural hispánico, 2009. 31-48. 